\title{
ON AN EFFECTIVE SOLUTION OF THE OPTIMAL STOPPING PROBLEM FOR RANDOM WALKS*
}

\author{
A. A. NOVIKOV ${ }^{\dagger}$ AND A. N. SHIRYAEV $\ddagger$
}

(Translated by the authors)

\begin{abstract}
We find a solution of the optimal stopping problem for the case when a reward function is an integer power function of a random walk on an infinite time interval. It is shown that an optimal stopping time is a first crossing time through a level defined as the largest root of Appell's polynomial associated with the maximum of the random walk. It is also shown that a value function of the optimal stopping problem on the finite interval $\{0,1, \ldots, T\}$ converges with an exponential rate as $T \rightarrow \infty$ to the limit under the assumption that jumps of the random walk are exponentially bounded.
\end{abstract}

Key words. optimal stopping, random walk, rate of convergence, Appell polynomials

DOI. $10.1137 / \mathrm{S} 0040585 \times 97981093$

\section{Introduction and the main result.}

1.1. Let $\xi, \xi_{1}, \xi_{2}, \ldots$ be a sequence of independent identically distributed random variables defined on a probability space $(\Omega, \mathcal{F}, \mathbf{P})$. Define a corresponding homogeneous Markov chain $X=\left(X_{0}, X_{1}, X_{2}, \ldots\right)$ such that

$$
X_{0}=x \in \mathbf{R}, \quad X_{k}=x+S_{k}, \quad S_{k}=\sum_{i=1}^{k} \xi_{i}, \quad k \geqq 1 .
$$

Let $P_{x}$ denote a distribution function which corresponds to the sequence $X$. In other words, the system $P_{x}, x \in \mathbf{R}$, and $X$ define a Markov family with respect to the flow of $\sigma$-algebras $\left(\mathcal{F}_{k}\right)_{k \geqq 0}, \mathcal{F}_{0}=\{\varnothing, \Omega\}, \mathcal{F}_{k}=\sigma\left\{\xi_{1}, \ldots, \xi_{k}\right\}$.

For the random walk under consideration we discuss the optimal stopping problem which consists of finding the "value" function

$$
V(x)=\sup _{\tau \in \overline{\mathfrak{M}}_{0}^{\infty}} E_{x} g\left(X_{\tau}\right) I\{\tau<\infty\}, \quad x \in \mathbf{R},
$$

where $g(x)$ is a measurable function, $I\{\cdot\}$ is the indicator function, and the supremum is taken over the class $\overline{\mathfrak{M}}_{0}^{\infty}$ of all stopping times $\tau$ with values in $[0, \infty]$ with respect to $\left(\mathcal{F}_{k}\right)_{k \geqq 0}$. We call a stopping time $\tau^{*}$ optimal if

$$
E_{x} g\left(X_{\tau^{*}}\right) I\left\{\tau^{*}<\infty\right\}=V(x), \quad x \in \mathbf{R} .
$$

We impose the following basic conditions on the random walk $X$ and the function $g(x)$ :

$$
\mathbf{E} \xi<0, \quad g(x)=\left(x^{+}\right)^{n}=(\max (x, 0))^{n}, \quad n=1,2, \ldots
$$

*Received by the editors July 1, 2002. This work was supported by UTS Large Grant A0010474; the second author was also supported by RFFI grant 02-01-00834.

http://www.siam.org/journals/tvp/49-2/98109.html

Steklov Mathematical Institute RAN, Gubkin St. 8, 119991 Moscow, Russia, and Department of Mathematical Sciences, Sydney University of Technology, P.O. Box 123, Broadway, Sydney, NSW 2007, Australia (Alex.Novikov@uts.edu.au).

ISteklov Mathematical Institute RAN, Gubkin St. 8, 119991 Moscow, Russia (albertsh@ mi.ras.ru). 
It is well known (see, e.g., [4], [11]) that under very general assumptions on $g(x)$ the solution of problem (1) can be characterized as follows: $V(x)$ is the least excessive majorant of the function $g(x)$, i.e., the smallest function $U=U(x)$ with the properties

$$
U(x) \geqq g(x), \quad U(x) \geqq T U(x),
$$

where $T U(x)=E_{x} U\left(X_{1}\right)=\mathbf{E} U(x+\xi)$.

It is also well known (see, e.g., [11]) that if the stopping time

$$
\tau^{*}=\inf \left\{k \geqq 0: V\left(X_{k}\right)=g\left(X_{k}\right)\right\}
$$

is finite $P_{x}$-a.s. for any $x \in \mathbf{R}$, then under very general assumptions on $g(x)$ it is optimal in the class $\mathfrak{M}_{0}^{\infty}$.

There are far fewer results in the literature about the optimality of the stopping time

$$
\tau^{*}=\inf \left\{k \geqq 0: X_{k} \in D^{*}\right\}
$$

such that, generally speaking, $P_{x}\left\{\tau^{*}=\infty\right\}>0$ for some $x \in \mathbf{R}$ (where $D^{*}=\{x \in \mathbf{R}$ : $V(x)=g(x)\}$ is the "stopping region" and we assume always that $\inf \{\varnothing\}=\infty)$.

We consider the case in which a stopping time is not finite, but nevertheless it is optimal (in the class $\overline{\mathfrak{M}}_{0}^{\infty}$ ). Note that the results described in [4], [11], present only qualitative features of the solution of the optimal stopping problem for Markov families but they do not present an effective method for finding $V(x)$ or for constructing the stopping region $D^{*}$. From this point of view it is always of interest to find both $V(x)$ and $D^{*}$ in an explicit form. A list of papers with results of this type contains, in particular, [6], where the existence of the optimal stopping time $\tau^{*} \in \overline{\mathfrak{M}}_{0}^{\infty}$ was proved for the case $g(x)=x^{+}$under the assumption that $\mathbf{E} \xi<0$ and it was shown that it has the threshold form

$$
\tau^{*}=\inf \left\{k \geqq 0: X_{k} \geqq a^{*}\right\},
$$

i.e., $D^{*}=\left\{x \in \mathbf{R}: x \geqq a^{*}\right\}$. Here the value of the threshold $a^{*}$ as well as the function $V(x)$ is completely determined by the distribution of the random variable

$$
M=\sup _{k \geqq 0} S_{k}, \quad S_{0}=0
$$

(we use everywhere, if possible, the same notation as in [6]).

1.2. The goal of this paper consists of the following: On the one hand we generalize the result of [6] to the case $g(x)=\left(x^{+}\right)^{n}$ with $n=2,3, \ldots ;$ on the other hand we suggest a different (compare to [6]) method for checking the optimality of the corresponding stopping times (which are of the threshold form as in [6]).

To formulate the basic result we need the following definition.

Let $\eta$ be a random variable such that $\mathbf{E} e^{\lambda|\eta|}<\infty$ for some $\lambda>0$. Define the polynomials $Q_{k}(y)=Q_{k}(y ; \eta), k=0,1,2, \ldots$, using the decomposition

$$
\frac{e^{u y}}{\mathbf{E} e^{u \eta}}=\sum_{k=0}^{\infty} \frac{u^{k}}{k !} Q_{k}(y) .
$$

The polynomials $Q_{k}(y), k=0,1,2, \ldots$ (defined with the help of the "generating" function $e^{u y} / \mathbf{E} e^{u \eta}$ ) are called Appell polynomials (also known as Sheffer polynomials; see, e.g., [13]). The polynomials $Q_{k}(y)$ can be represented with the help of the 
cumulants $\varkappa_{1}, \varkappa_{2}, \ldots$ of the random variable $\eta$. For example,

$$
\begin{gathered}
Q_{0}(x)=1, \quad Q_{1}(y)=y-\varkappa_{1}, \quad Q_{2}(y)=\left(y-\varkappa_{1}\right)^{2}-\varkappa_{2}, \\
Q_{3}(x)=\left(y-\varkappa_{1}\right)^{3}-3 \varkappa_{2}\left(y-\varkappa_{1}\right)-\varkappa_{3} .
\end{gathered}
$$

In fact, to define uniquely the polynomials $Q_{k}(y), k=1, \ldots, n$, it is sufficient to assume that $\mathbf{E}|\eta|^{n}<\infty$. Under this assumption,

$$
\frac{d}{d y} Q_{k}(y)=k Q_{k-1}(y), \quad k \leqq n
$$

(this property is also used sometimes as the definition of Appell polynomials). Note also that decomposition (2) implies that for any $x \in \mathbf{R}, y \in \mathbf{R}$, and $k=1,2, \ldots$

$$
Q_{k}(y ; \eta+x)=Q_{k}(y-x ; \eta) .
$$

We shall always use Appell polynomials generated by the random variable $M=$ $\sup _{k \geqq 0} S_{k}$, that is, always

$$
Q_{k}(y)=Q_{k}(y ; M)
$$

Theorem 1. Let $n=1,2, \ldots$ and be fixed. Assume

$$
g(x)=\left(x^{+}\right)^{n}, \quad \mathbf{E} \xi<0, \quad \mathbf{E}\left(\xi^{+}\right)^{n+1}<\infty .
$$

Let $a_{n}^{*}$ be the largest real root of the equation

$$
Q_{n}(y)=0
$$

and

$$
\tau_{n}^{*}=\inf \left\{k \geqq 0: X_{k} \geqq a_{n}^{*}\right\} .
$$

Then the stopping time $\tau_{n}^{*}$ is optimal:

$$
V_{n}(x):=\sup _{\tau \in \overline{\mathfrak{M}}_{0}^{\infty}} E_{x}\left(X_{\tau}^{+}\right)^{n} I\{\tau<\infty\}=E_{x}\left(X_{\tau_{n}^{*}}^{+}\right)^{n} I\left\{\tau_{n}^{*}<\infty\right\} ;
$$

furthermore,

(6)

$$
V_{n}(x)=\mathrm{E} Q_{n}(M+x) I\left\{M+x \geqq a_{n}^{*}\right\}
$$

Remark 1. For $n=1$ and $n=2$

$$
a_{1}^{*}=\mathbf{E} M, \quad a_{2}^{*}=\mathbf{E} M+\sqrt{\mathbf{D} M} .
$$

Some cases in which the distribution of $M$ can be found in an explicit form are described in [2, section 19]; see also some examples in [14] concerning explicit formulas for crossing times through a level for an upper-continuous random walk. Usually, to find $V_{n}(x)$ one needs, generally speaking, to know the distribution function of the random variable $M$. Numerical values of cumulants and the distribution function of $M$ can be found with the help of Spitzer's identity (see, e.g., [12]).

Remark 2. The method used for the proof of Theorem 1 allows us also to obtain corresponding results for other reward functions $g(x)$. As an illustration we consider the case $g(x)=1-e^{-x^{+}}$in Theorem 2 (see section 4 below). Note that in [6] the case $g(x)=\left(e^{x}-1\right)^{+}$(with a discounting time factor) was studied too. 
1.3. The idea of the proof of Theorem 1 is the following.

Together with $g(x)=\left(x^{+}\right)^{n}$, we consider the function $\hat{g}(x)=x^{n}$ and solve for this case the optimal stopping problem

$$
\widehat{V}_{n}(x)=\sup _{\tau \in \widehat{\mathfrak{M}}_{0}^{\infty}} E_{x} \widehat{g}\left(X_{\tau}\right) I\{\tau<\infty\}
$$

where $\widehat{\mathfrak{M}}_{0}^{\infty}$ is the class of special stopping times of the form $\widehat{\tau}=\tau_{a}, a \geqq 0$,

$$
\tau_{a}=\inf \left\{k \geqq 0: X_{k} \geqq a\right\} .
$$

Since on the set $\left\{\tau_{a}<\infty\right\}$ the equality $\hat{g}\left(X_{\tau_{u}}\right)=g\left(X_{\tau_{u}}\right)$ holds then, obviously, $\widehat{V}_{n}(x) \leqq V_{n}(x)$, as $V_{n}(x)$ (see (5)) is calculated over the class of stopping times $\widehat{\mathfrak{M}}_{0}^{\infty}$, which is larger than the corresponding class in (7).

Based on properties of the Appell polynomials, it is possible to solve problem (7) completely. It turns out (see sections 2 and 3 ) that

$$
\widehat{V}_{n}(x)=\mathbf{E} Q_{n}(M+x) I\left\{M+x \geqq a_{n}^{*}\right\}
$$

and the optimal stopping time is $\widehat{\tau}_{n}=\tau_{a_{n}^{*}}$ (in the class $\widehat{\mathfrak{M}}_{0}^{\infty}$ ).

Further, using again properties of the Appell polynomials, we manage to show that

$$
\widehat{V}_{n}(x) \geqq V_{n}(x), \quad x \in \mathbf{R} .
$$

Thus, taking into account the inequality $\widehat{V}_{n}(x) \leqq V_{n}(x)$, we get that $\widehat{V}_{n}(x)=V_{n}(x)$ and the stopping time $\widehat{\tau}_{n}=\tau_{a_{n}^{*}}$ is optimal in the class $\overline{\mathfrak{M}}_{0}^{\infty}$.

To carry out the indicated plan of the proof for Theorem 1 we have to list a number of auxiliary results for the maximum $M=\sup _{k \geq 0} S_{k}$ and some properties of the Appell polynomials. That will be done in section 2 . In section 3 the auxiliary optimal stopping problem (7) will be discussed and the details of the proof for Theorem 1 will be given. In section 4 we present a number of remarks and, in particular, formulate and prove Theorem 2 on optimal stopping for the reward function $g(x)=1-e^{-x^{+}}$. In the same section we will formulate and prove Theorem 3 about a rate of convergence as $T \rightarrow \infty$ for the value function of the optimal stopping problem for the reward functions $g(x)=\left(x^{+}\right)^{n}, n=1,2, \ldots$, and $g(x)=1-e^{-x^{+}}$on the finite interval $\{0,1, \ldots, T\}$.

2. Auxiliary results. In what follows we assume that $\xi, \xi_{1}, \xi_{2}, \ldots$ is a sequence of independent identically distributed random variables such that

$$
\mathrm{E} \xi<0, \quad S_{k}=\sum_{i=1}^{k} \xi_{i}, \quad k \geqq 1, \quad S_{0}=0, \quad M=\max _{k \geqq 0} S_{k} .
$$

LEMMA 1. The following properties hold:

(a) $\mathbf{P}\{M<\infty\}=1, \mathbf{P}\{M=0\}>0$, and

$$
M \stackrel{\text { law }}{=}(M+\xi)^{+} \text {. }
$$

(b) Let $\sigma_{a}=\inf \left\{k \geqq 0: S_{k} \geqq a\right\}, a \geqq 0$, and $\mathbf{E} e^{\lambda M}<\infty$ for some $\lambda \in \mathbf{R}$. Then for all $u \leqq \lambda$

$$
\mathbf{E} e^{\lambda\left(M-S_{\sigma_{a}}\right)} e^{u S_{\sigma_{a}}} I\left\{\sigma_{a}<\infty\right\}=\mathbf{E} e^{\lambda M} \mathbf{E} e^{u S_{\sigma_{a}}} I\left\{\sigma_{a}<\infty\right\}
$$


Proof. Property (a) is well known; see, e.g., [5, section 10.4, Theorem 4] and [2, section 15].

The left and right sides of (10) are finite due to the assumption about the finiteness of $\mathbf{E} e^{\lambda M}$. Equality (10) is implied by the fact that on the set $\left\{\sigma_{a}<\infty\right\}=\{M \geqq a\}$ the inequalities $S_{k}<S_{\sigma_{a}}$ with $k<\sigma_{a}$ hold and, hence, the following equality holds:

$$
M-S_{\sigma_{a}}=\sup _{k \geqq 0}\left(S_{k+\sigma_{a}}-S_{\sigma_{a}}\right) \text {. }
$$

Due to time homogeneity of sequence $S_{n}$ this implies that $M-S_{\sigma_{u}} \stackrel{\text { law }}{=} M$. Besides, note that the random variable $M-S_{\sigma_{a}}$ does not depend on events from $\sigma$-algebra $\mathcal{F}_{k}=\sigma\left\{\xi_{1}, \ldots, \xi_{k}\right\}$ on the set $\left\{\sigma_{a}=k\right\}$. This implies (10) due to the validity of the following equalities:

$$
\begin{aligned}
\mathbf{E} e^{\lambda\left(M-S_{a_{a}}\right)} e^{u S_{\sigma_{a}}} I\left\{\sigma_{a}<\infty\right\} & =\mathbf{E} \sum_{k=0}^{\infty} \mathbf{E}\left(e^{\lambda\left(M-S_{k}\right)} \mid \mathcal{F}_{k}\right) e^{u S_{\sigma_{a}}} I\left\{\sigma_{a}=k\right\} \\
& =\mathbf{E} e^{\lambda M} \mathbf{E} e^{u S_{a_{a}}} I\left\{\sigma_{a}<\infty\right\} .
\end{aligned}
$$

LEMMA 2.

(a) Let $\mathbf{E} e^{\lambda \xi}<1$ for some $\lambda>0$. Then for all $u \leqq \lambda$

$$
\mathbf{E} e^{u M}<\infty
$$

(b) For all $p>0$

$$
\mathbf{E}\left(\xi^{+}\right)^{p+1}<\infty \Longrightarrow \mathbf{E} M^{p}<\infty
$$

Proof. See [8], [2], [6], and also [9] concerning the upper bounds for $\mathbf{P}\{M>x\}$ which also imply (a).

LEMMA 3. Let $\tau_{a}=\inf \left\{k \geqq 0: X_{k} \geqq a\right\}, a \geqq 0$.

(a) If $\mathbf{E} e^{\lambda \xi}<1$ for some $\lambda \geqq 0$, then for all $a \geqq 0$ and $u \leqq \lambda$

$$
E_{x} I\left\{\tau_{a}<\infty\right\} e^{u X_{\tau_{a}}}=\frac{\mathbf{E} I\{M+x \geqq a\} e^{u(M+x)}}{\mathbf{E} e^{u M}} .
$$

(b) If $\mathbf{E}\left(\xi^{+}\right)^{n+1}<\infty$, then for all $a \geqq 0$

$$
E_{x} I\left\{\tau_{a}<\infty\right\} X_{\tau_{u}}^{n}=\mathrm{E} I\{M+x \geqq a\} Q_{n}(M+x) .
$$

Proof. (a) By Lemma 2 condition $\mathbf{E} e^{\lambda \xi}<1$ implies the finiteness of $\mathbf{E} e^{u M}$ for $u \leqq \lambda$.

If $x \geqq a$, then $\tau_{a}=0$ and (11) obviously holds. If $x<a$, then we can apply Lemma 1(b) with $\lambda=u$ :

$$
\begin{aligned}
E_{x} I\left\{\tau_{a}<\infty\right\} e^{u X_{\tau_{u}}} \mathbf{E} e^{u M} & =\mathbf{E} I\left\{\sigma_{a-x}<\infty\right\} e^{u\left(S_{\sigma_{a-x}}+x\right)} \mathbf{E} e^{u M} \\
& =\mathbf{E} I\left\{\sigma_{a-x}<\infty\right\} e^{u(M+x)}=\mathbf{E} I\{M+x \geqq a\} e^{u(M+x)}
\end{aligned}
$$

and this is equivalent to (11). 
(b) Let condition $\mathrm{E} e^{\lambda \xi}<1$ hold for some $\lambda>0$. Then both parts of (11) are, obviously, differentiable with respect to the parameter $u<\lambda$. Computing the $n$th derivative at the point $u=0$ and using definition (2) of the Appell polynomials, we get (12).

The fact that this relation holds also under the assumption $\mathbf{E}\left(\xi^{+}\right)^{n+1}<\infty$ can be proved with the standard trick of "truncation" for jumps as follows.

Together with the original random walk $S_{k}, k \geqq 0$, we consider a random walk $S_{k}^{(N)}$, $k \geqq 0$, generated by random variables $\xi^{(N)}=\min (\xi, N), N=1,2, \ldots$. Further we use index $N$ for all functionals which are related to $S_{k}^{(N)}, k \geqq 0$, exactly as they were used above for $S_{k}, k \geqq 0: M^{(N)}=\sup _{k \geqq 0} S_{k}^{(N)}, \tau_{a}^{(N)}=\inf \left\{k: X_{k}^{(N)} \geqq a\right\}$, etc.

By Lemma 2 the maximum $M^{(N)}$ is an exponentially bounded random variable (that is, $\operatorname{E} \exp \left\{\lambda M^{(N)}\right\}<1$ for some $\lambda>0$ ) and, hence, again by Lemma 2 equation (12) holds for the "truncated" random walk. Therefore, it is sufficient to check that condition $\mathbf{E}\left(\xi^{+}\right)^{n+1}<\infty$ implies, as $N \rightarrow \infty$,

$$
M^{(N)} \stackrel{\mathrm{d}}{\longrightarrow} M, \quad \mathbf{E}\left(M^{(N)}\right)^{k} \rightarrow \mathbf{E}(M)^{k}, \quad k=1, \ldots, n,
$$

and

$$
E_{x} I\left\{\tau_{a}^{(N)}<\infty\right\}\left(X_{\tau_{a}^{(N)}}^{(N)}\right)^{n} \rightarrow E_{x} I\left\{\tau_{a}<\infty\right\}\left(X_{\tau_{a}}\right)^{n} .
$$

The validity of these relations is implied by the integrability and monotonicity of the sequences $\left\{M^{(N)}\right\}$ and $\left\{X_{\tau_{0}^{(N)}}^{(N)}\right\}$ as $N \rightarrow \infty$.

LEMMA 4. Let $\mathbf{E}\left(\xi^{+}\right)^{n+1}<\infty$. Then

$$
\mathbf{E} Q_{n}(M+x)=x^{n} \text {. }
$$

Proof. At first assume that $\mathrm{E} e^{\lambda \xi}<1$ for some $\lambda>0$. Then by Lemma 2 we have $\mathbf{E} e^{\lambda M}<\infty$, and it follows from the definition of the Appell polynomials that

$$
e^{u x}=\frac{\mathbf{E} e^{u(M+x)}}{\mathbf{E} e^{u M}}=\sum_{k=0}^{\infty} \frac{u^{k}}{k !} \mathbf{E} Q_{k}(M+x), \quad 0 \leqq u<\lambda,
$$

which implies (13). The general case can be proved with the help of the "truncation" of jumps which has been described above.

Remark 3. The statement of Lemma 4 can be easily generalized to the case of Appell polynomials generated by an arbitrary random variable $\eta$ such that $\mathbf{E}|\eta|^{n}<\infty$ :

$$
\mathbf{E} Q_{n}(\eta+x ; \eta)=x^{n} \text {. }
$$

LEMMA 5. Let $n=1,2, \ldots$. Then $Q_{n}(y)$ has a unique positive root $a_{n}^{*}$ such that $a_{n}^{*}$, such that

$$
Q_{n}(y) \leqq 0 \quad \text { for } \quad 0 \leqq y<a_{n}^{*},
$$

and $Q_{n}(y)$ is an increasing function for $y \geqq a_{n}^{*}$.

Proof. For $n=1$ the statement of this lemma holds as $Q_{1}(y)=y-\mathbf{E} M$, $a_{1}^{*}=\mathbf{E} M>0$. For $n \geqq 2$, using property (3), we proceed by induction. At first we need to show that $Q_{n}(0) \leqq 0$ for all $n=1,2, \ldots$. 
Let $\sigma_{a}=\inf \left\{k: S_{k} \geqq a\right\}, a \geqq 0$. Set

$$
q(a, n):=\mathbf{E} I\left\{\tau_{a}<\infty\right\} S_{\sigma_{a}}^{n} .
$$

Obviously, we have $q(a, n) \geqq 0$ for all $a \geqq 0$. By Lemma $3(\mathrm{~b})$ with $x=0$

$$
q(a, n)=\mathbf{E} I\{M \geqq a\} Q_{n}(M) .
$$

Since by Lemma $4 \mathrm{E} Q_{n}(M)=0$, we have

$q(a, n)=-\mathbf{E} I\{M<a\} Q_{n}(M)=-\mathbf{P}\{M<a\} Q_{n}(0)+\mathbf{E} I\{M<a\}\left(Q_{n}(0)-Q_{n}(M)\right)$.

Using (3), we get

$$
\mathbf{E} I\{M<a\}\left|Q_{n}(M)-Q_{n}(0)\right| \leqq n a \max _{0 \leqq x \leqq a}\left|Q_{n-1}(x)\right| \mathbf{P}\{M<a\},
$$

and so

$$
q(a, n)=-\mathrm{P}\{M<a\} Q_{n}(0)+o(a) \quad \text { as } \quad a \rightarrow 0 .
$$

Since $q(a, n) \geqq 0$ and $\mathbf{P}\{M<a\} \geqq \mathbf{P}\{M=0\}>0$ (see Lemma 1) for all $a \geqq 0$, we then have the required inequality $Q_{n}(0) \leqq 0$ for all $n=1,2, \ldots$.

Now rewrite (3) as follows:

$$
Q_{n}(y)=Q_{n}(0)+n \int_{0}^{y} Q_{n-1}(u) d u
$$

Assume that for some $n>1$ the inequalities $Q_{n-1}(y) \leqq 0$ with $y \in\left[0, a_{n-1}^{*}\right]$ and $Q_{n-1}(y)>0$ with $y>a_{n-1}^{*}>0$ hold. Then we get that the polynomial $Q_{n}(y)$ is negative and decreasing on the interval $\left(0, a_{n-1}^{*}\right)$. Obviously, it reaches its minimum at the point $y=a_{n-1}^{*}$. For $y \geqq a_{n-1}^{*}$ the polynomial $Q_{n}(y)$ is increasing to infinity and, hence, there exists a root $a_{n}^{*}>a_{n-1}^{*}>0$. By induction this implies that the statement of the lemma holds for all $n=1,2, \ldots$.

LEMMA 6. Let

$$
f(x)=\mathbf{E} I\left\{M+x \geqq a^{*}\right\} G(M+x)<\infty,
$$

where the function $G(x)$ is such that

$$
G(y) \geqq G(x) \geqq G\left(a^{*}\right)=0 .
$$

Then for all $x$

$$
f(x) \geqq \mathbf{E} f(\xi+x)
$$

Proof. Inequality (16) is proved by the following chain of inequalities which exploit the property $M \stackrel{\text { law }}{=}(M+\xi)^{+}$(see Lemma 1$)$ :

$$
\begin{aligned}
f(x)= & \mathbf{E} I\left\{(M+\xi)^{+}+x \geqq a^{*}\right\} G\left((M+\xi)^{+}+x\right)=\mathbf{E} I\left\{x \geqq a^{*}, M+\xi<0\right\} G(x) \\
& +\mathbf{E} I\left\{M+\xi+x \geqq a^{*}, M+\xi \geqq 0\right\} G(M+\xi+x) \\
\geqq & \mathbf{E} I\left\{M+\xi+x \geqq a^{*}, M+\xi<0\right\} G(M+\xi+x) \\
& +\mathbf{E} I\left\{M+\xi+x \geqq a^{*}, M+\xi \geqq 0\right\} G(M+\xi+x)=\mathbf{E} f(x+\xi) .
\end{aligned}
$$


LEMMA 7. Let $f(x)$ and $g(x)$ be nonnegative functions such that for all $x$

$$
f(x) \geqq g(x)
$$

and

$$
f(x) \geqq \mathbf{E} f(\xi+x)
$$

Then for all $x$

$$
f(x) \geqq \sup _{\tau \in \overline{\mathfrak{M}}_{0}^{\infty}} \mathrm{E} I\{\tau<\infty\} g\left(S_{\tau}+x\right) .
$$

Proof. Conditions (17) and (18) imply the fact that the function $f(x)$ is an excessive majorant of $g(x)$. Now the required inequality is implied by Doob's theorem about preserving the supermartingale property under random stopping (see, e.g., [1], [3], [9]).

3. Proof of Theorem 1. Let $g(x)=\left(x^{+}\right)^{n}, \widehat{g}(x)=x^{n}$ with the function $\widehat{V}_{n}(x)$ defined as in (7). At first we demonstrate the validity of (8) that is

$$
\widehat{V}_{n}(x)=\sup _{a \geqq 0} E_{x} I\left\{\tau_{a}<\infty\right\} X_{\tau_{a}}^{n}=\mathbf{E} Q_{n}(M+x) I\left\{M+x \geqq a_{n}^{*}\right\} .
$$

To prove this equation note that by Lemma $3(\mathrm{~b})$

$$
E_{x} I\left\{\tau_{a}<\infty\right\} X_{\tau_{a}}^{n}=\mathbf{E} Q_{n}(M+x) I\{M+x \geqq a\},
$$

where $Q_{n}(M+x) \geqq 0$ on the set $\{M+x \geqq a\}$ for all $a \in\left[a_{n}^{*}, \infty\right)$. Hence, $\mathbf{E} Q_{n}(M+$ x) $I\{M+x \geqq a\}$ is a decreasing function on the interval $\left[a_{n}^{*}, \infty\right)$.

Now let $a \in\left[0, a_{n}^{*}\right]$. From (13) it follows that

$$
\begin{aligned}
\mathbf{E} Q_{n}(M+x) I\{M+x \geqq a\}= & x^{n}-\mathbf{E} Q_{n}(M+x) I\{M+x<0\} \\
& -\mathbf{E} Q_{n}(M+x) I\{0 \leqq M+x<a\} .
\end{aligned}
$$

Exploiting the fact that $Q_{n}(M+x) I\{0 \leqq M+x \leqq a\} \leqq 0$ (see Lemma 5) and, hence, that $\mathbf{E} Q_{n}(M+x) I\{0 \leqq M+x<a\}$ is a decreasing function, we conclude that $\mathbf{E} Q_{n}(M+x) I\{M+x \geqq a\}$ is an increasing function on the interval $\left[0, a_{n}^{*}\right]$. As this function is also decreasing on $\left[a_{n}^{*}, \infty\right)$ (as was shown above) and is, obviously, continuous (by the properties of Lebesgue integrals) for all $a$, then it achieves its maximum at the point $a=a_{n}^{*}$. Thus, (20) (as well as (8)) is proved.

To complete the proof we need only check inequality (9), that is, show that $\widehat{V}_{n}(x) \geqq V_{n}(x)$ (it has been already noted in section 1 that the opposite inequality is valid). To demonstrate this we consider the function

$$
f(x)=\widehat{V}_{n}(x)=\mathbf{E} I\left\{M+x \geqq a_{n}^{*}\right\} Q_{n}(M+x)
$$

and apply Lemma 7 with $g(x)=\left(x^{+}\right)^{n}$. At first let us check condition (17) for $x \in\left(0, a_{n}^{*}\right)$ (it is obvious). Note that for all $x \in\left(0, a_{n}^{*}\right)$ by Lemma 5

$$
I\left\{M+x \geqq a_{n}^{*}\right\} Q_{n}(M+x)=\left(Q_{n}(M+x)\right)^{+} .
$$

Hence, by Jensen's inequality and Lemma 4 ,

$$
f(x)=\mathbf{E}\left(Q_{n}(M+x)\right)^{+} \geqq\left(\mathbf{E} Q_{n}(M+x)\right)^{+}=\left(x^{+}\right)^{n}=g(x) .
$$

Condition (18) in Lemma 7 holds with $G(y)=Q_{n}(y)$ by Lemma 6 .

So the function $f(x)$ is an excessive majorant of $g(x)=\left(x^{+}\right)^{n}$ and, hence, $f(x) \geqq$ $V_{n}(x)$. But $f(x)=\widehat{V}_{n}(x)$, and, hence, $\widehat{V}_{n}(x) \geqq V_{n}(x)$.

Theorem 1 is proved. 
4. Some remarks.

Remark 4. The method of the proof of Theorem 1 may be used for other reward functions $g(x)$. To see an example, consider the following result.

THEOREM 2. Let $\mathrm{E} \xi<0$ and $g(x)=1-e^{-x^{+}}$. Set

$$
a^{*}=-\log \mathbf{E} e^{-M} \text {. }
$$

Then the stopping time

$$
\tau_{a^{*}}=\inf \left\{k \geqq 0: X_{k} \geqq a^{*}\right\}
$$

is optimal:

$$
V(x)=\sup _{\tau \in \overline{\mathfrak{M}}_{0}^{\infty}} E_{x} g\left(X_{\tau}\right) I\{\tau<\infty\}=E_{x} g\left(X_{\tau_{a^{*}}}\right) I\left\{\tau_{a^{*}}<\infty\right\}
$$

furthermore,

$$
V(x)=\mathbf{E}\left(1-\frac{e^{-M-x}}{\mathbf{E} e^{-M}}\right)^{+}
$$

Proof. We present here only a sketch of the proof, as it is similar to the proof of Theorem 1 (and even simpler).

Let $g(x)=1-e^{-x^{+}}$and

$$
\widehat{V}(x)=\sup _{a \geqq 0} E_{x} I\left\{\tau_{a}<\infty\right\} g\left(X_{\tau_{a}}^{n}\right) .
$$

At first let us show that

$$
\widehat{V}(x)=\mathbf{E}\left(1-\frac{e^{-M-x}}{\mathbf{E} e^{-M}}\right)^{+} .
$$

To see this, note that by Lemma 3 (a) with $u=-1$ the following equation holds:

$$
E_{x} I\left\{\tau_{a}<\infty\right\} e^{-X_{\tau_{a}}}=\frac{\mathbf{E} I\{M+x \geqq a\} e^{-(M+x)}}{\mathbf{E} e^{-M}},
$$

and, hence,

$$
q(a):=E_{x} I\left\{\tau_{a}<\infty\right\} g\left(X_{\tau_{a}}\right)=\mathbf{E} I\{M+x \geqq a\}\left(1-\frac{e^{-(M+x)}}{\mathbf{E} e^{-M}}\right) .
$$

Note also that the function $1-e^{-a} / \mathbf{E} e^{-M}$ is monotone in the argument $a$ with the unique root $a^{*}=-\log E e^{-M}$. The same considerations as were used in the proof of Theorem 1 demonstrate that $q(a)$ achieves its maximum at $a=a^{*}$ and

$$
\widehat{V}(x)=\mathbf{E} I\left\{M+x \geqq a^{*}\right\}\left(1-\frac{e^{-(M+x)}}{\mathbf{E} e^{-M}}\right)=\mathbf{E}\left(1-\frac{e^{-M-x}}{\mathbf{E} e^{-M}}\right)^{+} .
$$

To complete the proof we need only check inequality (9), that is, to show $\widehat{V}(x) \geqq$ $V(x)$. To do this consider the function

$$
f(x)=\widehat{V}(x)=\mathbf{E}\left(1-\frac{e^{-M-x}}{\mathbf{E} e^{-M}}\right)^{+}
$$


Condition (17) holds due to the Jensen inequality

$$
f(x) \geqq\left(1-\frac{\mathbf{E} e^{-M-x}}{\mathbf{E} e^{-M}}\right)^{+}=\left(1-e^{-x}\right)^{+}=g(x) .
$$

Condition (18) holds for $G(y)=\left(1-e^{-y} / \mathbf{E} e^{-M}\right)^{+}$by Lemma 6 . This completes the proof of Theorem 2.

Remark 5. A solution of the optimal stopping problem on the finite interval $\{0,1, \ldots, T\}$, with the "value" function

$$
V(x, T)=\sup _{\tau \in \mathfrak{M}_{\mathbf{0}}^{T}} E_{x} g\left(X_{\tau}\right), \quad x \in \mathbf{R},
$$

where the supremum is taken over all stopping times $\tau, \tau \leqq T<\infty$, can be obtained numerically using the well-known method of "backward induction" (see details, e.g., in [4], [11]). For large $T$ realization of this method could require a huge amount of calculations even for simple distributions. Therefore, it is of interest to estimate a rate of convergence of $V(x, T)$ as $T \rightarrow \infty$ to the function $V(x)$ described in Theorems 1 and 2.

Theorem 3. Let $g(x)=\left(x^{+}\right)^{n}, n=1,2, \ldots$ or $g(x)=1-e^{-x^{+}}$, and let $\mathbf{E} e^{\lambda \xi}<1$ for some $\lambda>0$. Then there exist constants $C(x)$ and $c$, which do not depend on $T$ and such that for each $x \in \mathbf{R}$ and all $T>0$

$$
0 \leqq V(x)-V(x, T) \leqq C(x) e^{-c T} .
$$

Proof. Since the class $\mathfrak{M}_{0}^{\infty}$ is larger than the class $\mathfrak{M}_{0}^{T}$, then $V(x) \geqq V(x, T)$. To obtain the upper bound (23), note that

$$
V(x, T) \geqq E_{x} g\left(X_{\min \left(\tau_{b}, T\right)}\right) \geqq E_{x} g\left(X_{\tau_{b}}\right) I\left\{\tau_{b} \leqq T\right\},
$$

where $\tau_{b}=\inf \left\{k \geqq 0: X_{k} \geqq b\right\}$ is the optimal stopping time for the value function $V(x)$ with (by Theorem 1 or 2) the parameter $b$ being equal to $a_{n}^{*}$ or $a^{*}$ accordingly to the form of the reward function $g(x)$. As $V(x)=E_{x} g\left(X_{\tau_{b}}\right) I\left\{\tau_{b}<\infty\right\}$, we obtain

$$
V(x)-V(x, T) \leqq E_{x} g\left(X_{\tau_{b}}\right) I\left\{T<\tau_{b}<\infty\right\} .
$$

Below we shall show that

$$
P_{x}\left\{T<\tau_{b}<\infty\right\} \leqq C(x) e^{-c T},
$$

where $C(x)$ and $c$ are some positive constants not depending on $T$. When the function $g(x)$ is bounded (as in Theorem 2), (25) and (24) imply immediately (23). For the case $g(x)=\left(x^{+}\right)^{n}, n=1,2, \ldots$, the same bound (25) in combination with Lemma 2(b) and Hölder's inequality implies (23) due to the inequality $X_{\tau_{b}} \leqq M$.

Let $\psi(u)$ be defined by the following equation:

$$
\mathbf{E} e^{u \xi}=e^{\psi(u)} \quad(u<\theta=\sup \{u \geqq 0: \psi(u)<\infty\}) .
$$

Note that $\psi(u)$ is a convex function and, due to the conditions of Theorem 3 , we have $\theta>0$. These properties imply that the derivative $\psi^{\prime}(0)=\mathbf{E} \xi<0$ and there exists 
positive $\lambda_{0} \in(0, \theta)$ such that $\psi^{\prime}\left(\lambda_{0}\right)=0$ and $\psi\left(\lambda_{0}\right)<0$ (see, e.g., [2]). To prove (25), one can use the fact that the process

$$
\exp \left\{\lambda\left(X_{k}-x\right)-k \psi(\lambda)\right\}, \quad k \geqq 0 \quad(\lambda \in(0, \theta))
$$

is a nonnegative martingale with the expectation

$$
\mathbf{E} \exp \left\{\lambda\left(X_{k}-x\right)-k \psi(\lambda)\right\}=1 .
$$

Therefore, it can be used to construct a new measure $A \in \sigma\left(\bigcup_{k \geq 0} \mathcal{F}_{k}\right)$ such that for each $k \geqq 0$ and a set $A \in F_{k}$

$$
\widehat{P}_{x}(A)=E_{x} I\{A\} \exp \left\{\lambda_{0}\left(X_{k}-x\right)-k \psi\left(\lambda_{0}\right)\right\} .
$$

(This is nothing else but the well-known Esscher transform.) With the notation given above we get

$$
\begin{aligned}
& E_{x} I\left\{T<\tau_{b}<\infty\right\} \exp \left\{\lambda_{0}\left(X_{\tau_{b}}-x\right)-\tau_{b} \psi\left(\lambda_{0}\right)\right\} \\
& =\sum_{k=T+1}^{\infty} E_{x} I\left\{\tau_{b}=k\right\} \exp \left\{\lambda_{0}\left(X_{k}-x\right)-k \psi\left(\lambda_{0}\right)\right\} \\
& =\sum_{k=T+1}^{\infty} \widehat{P}_{x}\left\{\tau_{b}=k\right\}=\widehat{P}_{x}\left\{T<\tau_{b}<\infty\right\}
\end{aligned}
$$

Since $X_{\tau_{b}} \geqq b$, it follows that

$$
P_{x}\left\{T<\tau_{b}<\infty\right\} \leqq e^{\lambda_{0}(x-b)} e^{\psi\left(\lambda_{0}\right) T} \widehat{P}_{x}\left\{T<\tau_{b}<\infty\right\}
$$

Taking into account that $\widehat{P}_{x}\left\{T<\tau_{b}<\infty\right\} \leqq 1$, we get bound (25) with constants $c=-\psi\left(\lambda_{0}\right)>0, C(x)=e^{\lambda_{0}(x-b)}, b=a_{n}^{*}$ or $b=a^{*}$, according to the form of function $g(x)$.

Theorem 3 is proved.

Remark 6. The results of this paper can be generalized to the case of stochastic processes with continuous time parameter (that is, for Lévy processes instead of the random walk). This generalization can be done by passage of the limit from the discrete time case (similarly to the technique used in [10] for pricing of American options) or by use of the technique of pseudodifferential operators (described, e.g., in monograph [3] in the context of Lévy processes).

Acknowledgments. The authors are thankful to E. Shinjikashvili for discussions of results. The first author is also thankful to Y. Miyahara and A. Shimizu for support and discussions during his visit to Nagoya City University.

\section{REFERENCES}

[1] D. BlaCKWELL, On optimal systems, Ann. Math. Statist., 25 (1954), pp. 394-397.

[2] A. Borovkov, Stochastic Processes in Queueing Theory, Springer-Verlag, New York, Berlin, 1976.

[3] S. BoYARChENKo AND S. Z. LeVENDORSKII,, Non-Gaussian Merton-Black-Scholes Theory, World Scientific, River Edge, NJ, 2002.

[4] Y. S. Chow, H. RobBins, AND D. SiEgmund, The Theory of Optimal Stopping, Dover, New York, 1991. 
[5] Y. S. Chow and T. TeICHER, Probability Theory: Independence, Interchangeability, Martingales, Springer-Verlag, New York, 1997.

[6] D. A. Darling, T. LiggetT, AND H. M. TAYloR, Optimal stopping for partial sums, Ann Math. Statist., 43 (1972), pp. 1363-1368.

[7] L. E. Dubins ANd L. J. SAVAGE, Inequalities for Stochastic Processes (How to Gamble if You Must), Dover, New York, 1976.

[8] J. F. C. KInGMaN, Inequalities in the theory of queues, J. Roy. Statist. Soc. Ser. B, 32 (1970), pp. 102-110.

[9] Z. LIU, P. NAIN, AND D. TOWsLEY, Bounds for a class of stochastic recursive equations, Math. Methods Oper. Res., 49 (1999), pp. 325-333.

[10] E. MORDECKI, Optimal stopping and perpetual options for Lévy processes, Finance Stoch., 6 (2002), pp. 473-493.

[11] A. N. ShIRYAEv, Statistical Sequential Analysis: Optimal Stopping Rules, Nauka, Moscow, 1969 (in Russian).

[12] W. STADJE, An iterative approximation procedure for the distribution of the maximum of a random walk, Statist. Probab. Lett., 50 (2000), pp. 375-381.

[13] W. Schoutens, Stochastic Processes and Orthogonal Polynomials, Springer-Verlag, New York, 2000.

[14] $\mathrm{O} . \mathrm{V}$. VISKov, A random walk with a skip-free component, and the Lagrange inversion formula, Theory Probab. Appl., 45 (2000), pp. 164-172. 
РОССИЙСКАЯ АКАДЕМИЯ НАУК

\section{ТЕОРИЯ \\ ВЕРОЯТНОСТЕЙ \\ И ЕЕ ПРИМЕНЕНИЯ}

Журнал имени А.Н.Колмогорова

TOM 49

(о тде льны й о т ти ск)

MOCKBA 2004 
28. Егоров B.A. Об асимптотическом поведении самонормированных сумм случайных величин. - Теория вероятн. и ее примен., 1996, т. 41, в. 3, с. 643-650.

29. Чистиков $\Gamma$. П. Новое асимптотическое разложение и асимптотически наилучшие постоянные в теореме Ляпунова. I. - Теория вероятн. и ее примен., 2001, т. 46, B. 2 , c. $326-344$.

30. Bloznelis M., Putter H. Second order and bootstrap approximation to Student's $t$ statistic. - Теория вероятн. и ее примен., 2002, т. 47, в. 2, с. 374-381.

Поступила в редакцию 15.X.2001

(C) $2004 \mathrm{r}$.

НОВИКОВ А. А.*, ШИРЯЕВ А. Н.**

\section{ОБ ОДНОМ ЭФФЕКТИВНОМ СЛУЧАЕ РЕШЕНИЯ \\ ЗАДАЧИ ОБ ОПТИМАЛЬНОЙ ОСТАНОВКЕ ДЛЯ СЛУЧАЙНЫХ БЛУЖДАНИЙ ${ }^{1)}$}

В работе найдено решение задачи об оптимальной остановке в случае, когда функция выплат является целой степенной функцией от случайного блуждания, рассматриваемого на бесконечном временном интервале. При этом показано, что оптимальным является момент первого пересечения уровня, определяемого как наибольший корень полинома Аппеля, ассопиированного с распределением максимума случайного блуждания. Показано также, что в задаче об оптимальной остановке на конечном временном интервале $\{0,1, \ldots, T\}$ дена сходится при $T \rightarrow \infty$ с экспоненциальной скоростью к найденному пределу, когда скачки случайного блуждания экспоненциаљьно ограничены сверху.

Ключевые слова и фразы: оптимальная остановка, случайное блуждание, скорость сходимости, полиномы Аппеля.

\section{§1. Введение и основной результат}

1. Пусть $\xi, \xi_{1}, \xi_{2}, \ldots$ - последовательность независимых одинаково распределенных случайных величин, заданных на вероятностном пространстве $(\Omega, \mathscr{F}, \mathbf{P})$. Свяжем с этой последовательностью однородную марковскую цепь $X=\left(X_{0}, X_{1}, X_{2}, \ldots\right)$ такую, что

$$
X_{0}=x \in \mathbf{R}, \quad X_{k}=x+S_{k}, \quad S_{k}=\sum_{i=1}^{k} \xi_{i}, \quad k \geqslant 1 .
$$

Через $P_{x}$ будем обозначать распределение вероятностей, отвечающее последовательности $X$. Иначе говоря, система $P_{x}, x \in \mathbf{R}, \mathbf{n} X$ задают марковское семейство относительно потока $\sigma$-алгебр $\left(\mathscr{F}_{k}\right)_{k \geqslant 0}, \mathscr{F}_{0}=\{\varnothing, \Omega\}, \mathscr{F}_{k}=\sigma\left\{\xi_{1}, \ldots, \xi_{k}\right\}$.

Для рассматриваемото случайного блуждания в работе обсуждается задача об оптимальной остановке, состоящая в отыскании функции «цены»

$$
V(x)=\sup _{r \in \overline{\mathfrak{M}}_{0}^{\infty}} E_{x} g\left(X_{\tau}\right) I\{\tau<\infty\}, \quad x \in \mathbf{R}
$$

* Математический институт им. В.А. Стеклова РАН; Department of Mathematical Sciences, Sydney University of Technology, PO BOX 123, Broadway, Sydney, NSW 2007, Australia; e-mail: alex.novikov@uts.edu.au

** Математический институт им. В. А. Стеклова РАН, ул. Губкина, 8, 119991 Москва, ГСП-1, Россия; e-mail: albertsh@mi.ras.ru

1) Работа выполнена при поддержке ARC Large Grant A0010474; работа второго автора поддержана также Российским фондом фундаментальных исследований (грант 02-01-00834). 
где $g(x)$ - измеримая функция, $I\{\cdot\}$ - индикаторная функция и супремум берется по классу $\overline{\mathfrak{M}}_{0}^{\infty}$ всех марковских моментов $\tau$ со значениями в $[0, \infty]$ и относительно $\left(\mathscr{F}_{k}\right)_{k} \geqslant 0$. Мы называем оптимальным момент остановки $\tau^{*}$ такой, что

$$
E_{x} g\left(X_{\tau^{*}}\right) I\left\{\tau^{*}<\infty\right\}=V(x), \quad x \in \mathbf{R} .
$$

Основные предположения относительно случайного блуждания $X$ и функции $g(x)$ следуюшие:

$$
\mathbf{E} \xi<0, \quad g(x)=\left(x^{+}\right)^{n}=(\max (x, 0))^{n}, \quad n=1,2, \ldots
$$

Хорошо известно (см., например, [4], [11]), что при весьма широких предположениях о функции $g(x)$ решение задачи (1) может быть охарактеризовано следуюшим образом: $V(x)$ есть наименьшая эксцессивная мажоранта функции $g(x)$, т.е. наименьшая из функций $U=U(x)$ со свойствами

$$
U(x) \geqslant g(x), \quad U(x) \geqslant T U(x),
$$

rде $T U(x)=E_{x} U\left(X_{1}\right)=\mathbf{E} U(x+\xi)$.

При этом, опять же при весьма пироких предположениях о функции $g(x)$, известно (см. [11]), что если марковский момент

$$
r^{*}=\inf \left\{k \geqslant 0: V\left(X_{k}\right)=g\left(X_{k}\right)\right\}
$$

является конечным $P_{x}$-п.н. при всех $x \in \mathbf{R}$, то он является оптимальньик в классе $\mathfrak{M}_{0}^{\infty}$ (марковских моментов со значениями в $[0, \infty)$ ).

В литературе известно меньше результатов относительно оптимальности момента

$$
\tau^{*}=\inf \left\{k \geqslant 0: X_{k} \in D^{*}\right\}
$$

(где «область остановки» $D^{*}=\{x \in \mathbf{R}: V(x)=g(x)\}$ и мы всегда полагаем $\inf \{\varnothing\}=\infty$ ) такого, что, вообще говоря, $P_{x}\left\{\tau^{*}=\infty\right\}>0$ для некоторых $x \in \mathbf{R}$.

В рассматриваемой нами ситуашии мы как раз имеем случай, когца момент остановки не является хонеиным, но, тем не менее, оптимален (в классе $\overline{\mathfrak{M}}_{0}^{\infty}$ ). Отметим, что результаты, описанные в [4], [11], дают лишь качественное описание решения задач об оптимальной остановке для марковских семейств, но не дают эффективного способа отыскания функции $V(x)$ или построения области остановки $D^{*}$. С этой точки зрения всегда интересны те работы, в которых удается отыскать и $V(x)$, и $D^{*}$. K их числу можно отнести статью [6], в которой для функции $g(x)=x^{+}$в предположении $\mathbf{E} \xi<0$ устанавливается, что оптимаљьнй момент остановки $\tau^{*} \in \overline{\mathfrak{M}}_{0}^{\infty}$ существует и имеет пороговую структуру:

$$
\tau^{*}=\inf \left\{k \geqslant 0: X_{k} \geqslant a^{*}\right\}
$$

т.е. $D^{*}=\left\{x \in \mathbf{R}: x \geqslant a^{*}\right\}$, где значение порога $a^{*}$, а также функция $V(x)$ полностью определяются по распределенио величины

$$
M=\sup _{k \geqslant 0} S_{k}, \quad S_{0}=0
$$

(мы используем, по возможности, те же обозначения, что и в [6]).

2. Цель настоящей работы состоит в следующем: с одной стороны, мы обобшаем результаты работы [6] на случай функций $g(x)=\left(x^{+}\right)^{n}$ при $n=2,3, \ldots$; с другой стороны, мы предлагаем иной, нежели в [6], метоп установления оптимальности соответствуюших моментов остановки (которые, как и в [6], оказываются порогового типа).

Для формулировки основного результата работы - теоремы 1 , нам потребуется следуюшее определение.

Пусть $\eta-$ случайная величина такая, тто $\mathbf{E} e^{\lambda|\eta|}<\infty$ для некоторого $\lambda>0$. Определим полиномы $Q_{k}(y)=Q_{k}(y ; \eta), k=0,1,2, \ldots$, из разложения

$$
\frac{e^{u y}}{\mathbf{E} e^{u \eta}}=\sum_{k=0}^{\infty} \frac{u^{k}}{k !} Q_{k}(y) \text {. }
$$

Так определенные (по «производяшей» функции $e^{u y} / \mathbf{E} e^{u \eta}$ ) полиномы $Q_{k}(y)$, $k=0,1,2, \ldots$, носят название полиномов Anпеля (их называют также поликомами 
Шеффера, см., например, [13]). Полиномы $Q_{k}(y)$ могут быть выражены через кумулянты $\varkappa_{1}, \varkappa_{2}, \ldots$ величины $\eta$. Например,

$$
\begin{gathered}
Q_{0}(x)=1, \quad Q_{1}(y)=y-\varkappa_{1}, \quad Q_{2}(y)=\left(y-\varkappa_{1}\right)^{2}-\varkappa_{2}, \\
Q_{3}(x)=\left(y-\varkappa_{1}\right)^{3}-3 \varkappa_{2}\left(y-\varkappa_{1}\right)-\varkappa_{3} .
\end{gathered}
$$

Заметим, что для однозначного определения полиномов $Q_{k}(y), k=1, \ldots, n$, достаточно, на самом деле, требовать лишь, чтобы $\mathbf{E}|\eta|^{n}<\infty$. При этом

$$
\frac{d}{d y} Q_{k}(y)=k Q_{k-1}(y), \quad k \leqslant n
$$

(это свойство иногда берется за определение полиномов Аппеля). Отметим также, что из определения (2) следует, что для всех $x \in \mathbf{R}, y \in \mathbf{R}$ и $k=1,2, \ldots$

$$
Q_{k}(y ; \eta+x)=Q_{k}(y-x ; \eta) .
$$

Всюду в дальнейшем мы будем оперировать с полиномами Аппеля, порожденными случайной величиной $M=\sup _{k \geqslant 0} S_{k}$, т.е. всегда

$$
Q_{k}(y)=Q_{k}(y ; M) \text {. }
$$

Теорема 1. Пусть $n=1,2, \ldots$ и бихсироваяо. Предположсим, ито

$$
g(x)=\left(x^{+}\right)^{n}, \quad \mathbf{E} \xi<0, \quad \mathbf{E}\left(\xi^{+}\right)^{n+1}<\infty .
$$

Пусть $a_{n}^{*}-$ наибольиนй корень уравнения

$$
Q_{n}(y)=0
$$

$$
\tau_{n}^{*}=\inf \left\{k \geqslant 0: X_{k} \geqslant a_{n}^{*}\right\}
$$

Тогда момент остановки $\tau_{n}^{*}$ ввляется оптимальньи:

$$
V_{n}(x):=\sup _{\tau \in \overline{\mathfrak{M}}_{0}^{\infty}} E_{x}\left(X_{\tau}^{+}\right)^{n} I\{\tau<\infty\}=E_{x}\left(X_{\tau_{n}^{*}}^{+}\right)^{n} I\left\{\tau_{n}^{*}<\infty\right\}
$$

при эmом

$$
V_{n}(x)=\mathbf{E} Q_{n}(M+x) I\left\{M+x \geqslant a_{n}^{*}\right\} .
$$

3 а м е ч а и е 1. В случаях $n=1$ и $n=2$

$$
a_{1}^{*}=\mathbf{E} M, \quad a_{2}^{*}=\mathbf{E} M+\sqrt{\mathbf{D} M}
$$

Случаи, когда распределение $M$ находится в явном виде, описаны в $[2, \S 19]$; см. также некоторые примеры в работе [14] относительно явньх формул для моментов пересечения уровня полунепрерывными случайными блужданиями. В общем случае для нахождения $V_{n}(x)$, вообще говоря, нужно знать функцио распределения спучайной величины $M$. Численнте значения кумулянтов и функшия распределения случайной величины $M$ можно найти с помошњю тождества Спшера (см., например, [12]).

3 а м е ч а н и е 2. Метод доказательства теоремы 1 позволяет также получать соответствуюшие результаты и для других функшй $g(x)$. В теореме 2 (см. 44 ниже) в качестве иллострации рассмотрен случай $g(x)=1-e^{-x^{+}}$. Отметим, что в [6] рассмотрен также случай функщии $g(x)=\left(e^{x}-1\right)^{+}$(с дисконтированием по времени).

3. Идея доказательства теоремы 1 состоит в следующем.

Наряду с функцией $g(x)=\left(x^{+}\right)^{n}$ рассмотрим функпио $\widehat{g}(x)=x^{n}$ и решим для нее задачу об оптиматьной остановке

$$
\widehat{V}_{n}(x)=\sup _{\tau \in \widehat{\mathfrak{M}}_{0}^{\infty}} E_{x} \widehat{g}\left(X_{\tau}\right) I\{\tau<\infty\},
$$

где $\widehat{\mathfrak{M}}_{0}^{\infty}$ - класс моментов остановки специального вида: $\widehat{\tau}=\tau_{a}, a \geqslant 0$, где

$$
\tau_{a}=\inf \left\{k \geqslant 0: X_{k} \geqslant a\right\} .
$$

Так как на множестве $\left\{\tau_{a}<\infty\right\}$ имеем равенство $\hat{g}\left(X_{\tau_{a}}\right)=g\left(X_{\tau_{a}}\right)$, то, очевидно, $\widehat{V}_{n}(x) \leqslant V_{n}(x)$, посколыку $V_{n}(x)$ определяется (см. (5)) по более широкому классу моментов остановки $\overline{\mathfrak{M}}_{0}^{\infty}$, нежели в (5). 
Основываясь на свойствах полиномов Аппеля, можно дать исчерпывающее решение задачи (5): оказывается (см. §2 и §3), что

$$
\widehat{V}_{n}(x)=\mathbf{E} Q_{n}(M+x) I\left\{M+x \geqslant a_{n}^{*}\right\}
$$

и оптимальный момент $\widehat{\tau}_{n}=\tau_{a_{n}^{*}}\left(\right.$ в классе $\left.\widehat{\mathfrak{M}}_{0}^{\infty}\right)$.

Далее, опять же используя свойства полиномов Аппеля, удается показать, что

$$
\widehat{V}_{n}(x) \geqslant V_{n}(x), \quad x \in \mathbf{R} .
$$

Тем самым, учитывая неравенство $\widehat{V}_{n}(x) \leqslant V_{n}(x)$, находим, что $\widehat{V}_{n}(x)=V_{n}(x)$ и что момент $\widehat{\tau}_{n}=\tau_{a_{n}^{*}}$ является оптимальным в классе $\overline{\mathfrak{M}}_{0}^{\infty}$.

Осуцествление намеченного пути доказательства теоремы 1 требует ряда вспомогательных утверждений относительно свойств максимума $M=\sup _{k \geqslant 0} S_{k}$ и свойств полиномов Аппеля. Этому посвящен §2. В §3 рассматривается вспомогательная задача об оптимальной остановке (5) и приводятся детали доказательства теоремы 1. В §4 приводится ряд замечаний и, в частности, формулируется и доказывается теорема 2 о решении задачи об оптимальной остановке для функции $g(x)=1-e^{-x^{+}}$. Там же формулируется и доказывается теорема 3 о скорости сходимости при $T \rightarrow \infty$ функции цены задачи об оптимальной остановке на конечном интервале $\{0,1, \ldots, T\}$ для $g(x)=\left(x^{+}\right)^{n}, n=1,2, \ldots$, и $g(x)=1-e^{-x^{+}}$.

\section{§2. Вспомогательные результаты}

Мы всегда предполагаем ниже, что $\xi, \xi_{1}, \xi_{2}, \ldots$ - последовательность независимых одинаково распределенных случайных величин и

$$
\mathbf{E} \xi<0, \quad S_{k}=\sum_{i=1}^{k} \xi_{i}, \quad k \geqslant 1, \quad S_{0}=0, \quad M=\max _{k \geqslant 0} S_{k} .
$$

Лемма 1. Имеют место следуюиие свойства:

(a) $\mathbf{P}\{M<\infty\}=1, \mathbf{P}\{M=0\}>0 u$

$$
M \stackrel{\text { law }}{=}(M+\xi)^{+} \text {. }
$$

(b) $\Pi$ ycmb $\sigma_{a}=\inf \left\{k \geqslant 0: S_{k} \geqslant a\right\}, a \geqslant 0, u \mathbf{E} e^{\lambda M}<\infty$ dsq нехоторого $\lambda \in \mathbf{R}$. Tогда прu всех $u \leqslant \lambda$

$$
\mathbf{E} e^{\lambda\left(M-S_{\sigma_{a}}\right)} e^{u S_{\sigma_{a}}} I\left\{\sigma_{a}<\infty\right\}=\mathbf{E} e^{\lambda M} \mathbf{E} e^{u S_{\sigma_{a}}} I\left\{\sigma_{a}<\infty\right\} .
$$

Д ок а з а те л в с т в о. Свойства (а) хорошо известны - см., например, [5, раздел 10.4 , теорема 4] и $[2, \S 15]$.

Левая и правая части (10) конечны в силу предположения о конечности $\mathbf{E} e^{\lambda M}$. Само равенство (10) следует из того факта, что на множестве $\left\{\sigma_{a}<\infty\right\}=\{M \geqslant a\}$ выполнены неравенства $S_{k}<S_{\sigma_{a}}$ для $k<\sigma_{a}$ и, значит, имеет место равенство

$$
M-S_{\sigma_{a}}=\sup _{k \geqslant 0}\left(S_{k+\sigma_{a}}-S_{\sigma_{a}}\right) \text {. }
$$

В силу временной однородности последоватељњности $S_{n}$ отсюда следует, что $M-S_{\sigma_{a}} \stackrel{\text { law }}{=} M$. Заметим, кроме того, что случайная величина $M-S_{\sigma_{a}}$ на множестве $\left\{\sigma_{a}=k\right\}$ не зависит от событий из $\sigma$-алгебры $\mathscr{F}_{k}=\sigma\left\{\xi_{1}, \ldots, \xi_{k}\right\}$. Это обстоятельство и влечет свойство (10) ввиду следующих равенств:

$$
\begin{aligned}
\mathbf{E} e^{\lambda\left(M-S_{\sigma_{a}}\right)} e^{u S_{\sigma_{a}}} I\left\{\sigma_{a}<\infty\right\} & =\mathbf{E} \sum_{k=0}^{\infty} \mathbf{E}\left(e^{\lambda\left(M-S_{k}\right)} \mid \mathscr{F}_{k}\right) e^{u S_{\sigma_{a}}} I\left\{\sigma_{a}=k\right\} \\
& =\mathbf{E} e^{\lambda M} \mathbf{E} e^{u S_{\sigma_{a}}} I\left\{\sigma_{a}<\infty\right\} .
\end{aligned}
$$

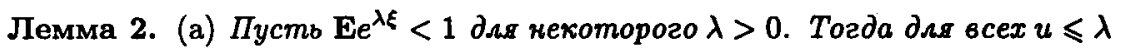

$$
\mathbf{E} e^{u M}<\infty .
$$

(b) Дия любого $p>0$

$$
\mathbf{E}\left(\xi^{+}\right)^{p+1}<\infty \Longrightarrow \mathbf{E} M^{p}<\infty .
$$


Д ок а з а т л в с т в о. См. работы [8], [2], [6], а также работу [9] относительно верхних оценок для $\mathbf{P}\{M>x\}$, которые также влекут утверждение (a).

Лемма 3. Пусть $\tau_{a}=\inf \left\{k \geqslant 0: X_{k} \geqslant a\right\}, a \geqslant 0$.

(a) Ecлu $\mathbf{E} e^{\lambda \xi}<1$ dлs некоторого $\lambda \geqslant 0$, mo dss всех $a \geqslant 0 u u \leqslant \lambda$

$$
E_{x} I\left\{\tau_{a}<\infty\right\} e^{u X_{\tau_{a}}}=\frac{\mathbf{E} I\{M+x \geqslant a\} e^{u(M+x)}}{\mathbf{E} e^{u M}} .
$$

(b) Ecлu $\mathbf{E}\left(\xi^{+}\right)^{n+1}<\infty$, mo dлs всеx $a \geqslant 0$

$$
E_{x} I\left\{\tau_{a}<\infty\right\} X_{\tau_{a}}^{n}=\mathbf{E} I\{M+x \geqslant a\} Q_{n}(M+x) .
$$

Док аз ат ельст в о. (а) По лемме 2 условие $\mathbf{E} e^{\lambda \xi}<1$ влечет конечность $\mathbf{E} e^{u M}$ для $u \leqslant \lambda$.

Если $x \geqslant a$, то $\tau_{a}=0$ и равенство (11) очевидно. При $x<a$ мы можем применить утверждение леммы 1 (b) с $\lambda=u$ :

$$
\begin{aligned}
E_{x} I\left\{\tau_{a}<\infty\right\} e^{u X_{\tau_{a}}} \mathbf{E} e^{u M} & =\mathbf{E} I\left\{\sigma_{a-x}<\infty\right\} e^{u\left(S_{\sigma_{a-x}}+x\right)} \mathbf{E} e^{u M} \\
& =\mathbf{E} I\left\{\sigma_{a-x}<\infty\right\} e^{u(M+x)}=\mathbf{E} I\{M+x \geqslant a\} e^{u(M+x)},
\end{aligned}
$$

что эквивалентно соотношению (11).

(b) Пусть выполнено условие $\mathbf{E} e^{\lambda \xi}<1$ при некотором $\lambda>0$. Тогда, очевидно, возможно дифференцирование в обеих частях (11) по параметру $u<\lambda$. Вычисляя $n$-ю производную в точке $u=0$, на основании определения полиномов Аппеля (2) получаем (12).

То, что это соотношение остается справедливым и только в предположении $\mathbf{E}\left(\xi^{+}\right)^{n+1}<\infty$, доказывается с помошью стандартного приема «усечения» скачков, состоящего в следуюшем.

Наряду с исходным случайныт блужданием $S_{k}, k \geqslant 0$, рассмотрим случайное блуждание $S_{k}^{(N)}, k \geqslant 0$, порожденное случайной величиной $\xi^{(N)}=\min (\xi, N)$, $N=1,2, \ldots$ Далее будем использовать индекс $N$ для всех функционалов, определяемых по $S_{k}^{(N)}, k \geqslant 0$, таким же образом, как и выпте для $S_{k}, k \geqslant 0: M^{(N)}=\sup _{k \geqslant 0} S_{k}^{(N)}$, $\tau_{a}^{(N)}=\inf \left\{k: X_{k}^{(N)} \geqslant a\right\}$ и т.д.

В силу леммы 2 максимум $M^{(N)}$ является экспоненциально ограниченной стучайной величиной (т.е. $\mathbf{E} \exp \left\{\lambda M^{(N)}\right\}<1$ для некоторого $\lambda>0$ ), и, значит, снова по лемме 2, соотношение (12) выполнено для «усеченного» случайного блуждания. Поэтому достаточно только проверить, что условие $\mathbf{E}\left(\xi^{+}\right)^{n+1}<\infty$ влечет, что при $N \rightarrow \infty$

и

$$
M^{(N)} \stackrel{\mathrm{d}}{\longrightarrow} M, \quad \mathbf{E}\left(M^{(N)}\right)^{k} \rightarrow \mathbf{E}(M)^{k}, \quad k=1, \ldots, n,
$$

$$
E_{x} I\left\{\tau_{a}^{(N)}<\infty\right\}\left(X_{\tau_{a}^{(N)}}^{(N)}\right)^{n} \rightarrow E_{x} I\left\{\tau_{a}<\infty\right\}\left(X_{\tau_{a}}\right)^{n}
$$

Выполнение этих свойств непосредственно следует из интегрируемости и монотонности последовательностей $\left\{M^{(N)}\right\}$ и $\left\{X_{\tau_{a}^{(N)}}^{(N)}\right\}$ при $N \rightarrow \infty$.

Лемма 4. $\Pi_{y c m b} \mathbf{E}\left(\xi^{+}\right)^{n+1}<\infty$. Тогдa

$$
\mathbf{E} Q_{n}(M+x)=x^{n} \text {. }
$$

Д ок а з а т е л с т в о. Предположим сначала, что $\mathbf{E} e^{\lambda \xi}<1$ при некотором $\lambda>0$. Тогда по лемме $2 \mathrm{E} e^{\lambda M}<\infty$, и из определения полиномов Аптеля следует, что

$$
e^{u x}=\frac{\mathbf{E} e^{u(M+x)}}{\mathbf{E} e^{u M}}=\sum_{k=0}^{\infty} \frac{u^{k}}{k !} \mathbf{E} Q_{k}(M+x), \quad 0 \leqslant u<\lambda .
$$

Отсюда легко следует (13). Обший случай доказывается с помошью уже описанного выше приема «усечения» скачков.

3 а м е ч а н и е 3 . Утверждение леммы 4 легко обобшается на случай полиномов Аппеля, порожденных произвольной случайной величиной $\eta$ такой, что $\mathbf{E}|\eta|^{n}<\infty: \mathbf{E} Q_{n}(\eta+x ; \eta)=x^{n}$. 
Лемма 5. Пусть $n=1,2, \ldots$. Тогда полином $Q_{n}(y)$ имеет единственньй положительный хорень $a_{n}^{*}$, причем

$u Q_{n}(y)$ возрастаem $\partial \Omega я y \geqslant a_{n}^{*}$

$$
Q_{n}(y) \leqslant 0 \quad \partial n g \quad 0 \leqslant y<a_{n}^{*}
$$

Д о к а з ат е л ь т в о. При $n=1$ утверждение леммы выполнено, поскольку $Q_{1}(y)=y-\mathbf{E} M, a_{1}^{*}=\mathbf{E} M>0$. Дальше доказательство будет проведено по индукции на основе свойства (3). Для этого нам нужно, прежде всего, показать, что $Q_{n}(0) \leqslant 0$ при всех $n=1,2, \ldots$

Пусть $\sigma_{a}=\inf \left\{k: S_{k} \geqslant a\right\}, a \geqslant 0$. Обозначим

$$
q(a, n):=\mathbf{E} I\left\{\tau_{a}<\infty\right\} S_{\sigma_{a}}^{n} .
$$

Очевидно, $q(a, n) \geqslant 0$ при всех $a \geqslant 0$. В силу леммы $3(\mathrm{~b})$ с $x=0$

$$
q(a, n)=\mathbf{E} I\{M \geqslant a\} Q_{\boldsymbol{n}}(M) \text {. }
$$

Так как по лемме $4 \mathrm{E} Q_{n}(M)=0$, то

$$
\begin{gathered}
q(a, n)=-\mathbf{E} I\{M<a\} Q_{n}(M)=-\mathbf{P}\{M<a\} Q_{n}(0)+\mathbf{E} I\{M<a\}\left(Q_{n}(0)-Q_{n}(M)\right) . \\
\text { Используя (3), получим } \\
\mathbf{E} I\{M<a\}\left|Q_{n}(M)-Q_{n}(0)\right| \leqslant n a \max _{0 \leqslant x \leqslant a}\left|Q_{n-1}(x)\right| \mathbf{P}\{M<a\},
\end{gathered}
$$

и поэтому

$$
q(a, n)=-\mathbf{P}\{M<a\} Q_{n}(0)+o(a) \quad \text { при } \quad a \rightarrow 0 .
$$

Так как $q(a, n) \geqslant 0$ и $\mathbf{P}\{M<a\} \geqslant \mathbf{P}\{M=0\}>0$ (см. лемму 1) при всех $a \geqslant 0$, то отсюда получаем требуемое свойство $Q_{n}(0) \leqslant 0$ для всех $n=1,2, \ldots$.

Запишем соотношение (3) в следуюшем виде:

$$
Q_{n}(y)=Q_{n}(0)+n \int_{0}^{y} Q_{n-1}(u) d u .
$$

Предполагая по индукции, что при некотором $n>1$ выполнены неравенства $Q_{n-1}(y) \leqslant 0$ для $y \in\left[0, a_{n-1}^{*}\right]$ и $Q_{n-1}(y)>0$ для $y>a_{n-1}^{*}>0$, получим, что полином $Q_{n}(y)$ отрицателен и убывает на интервале $\left(0, a_{n-1}^{*}\right)$ и достигает своего минимума в точке $y=a_{n-1}^{*}$. При $y \geqslant a_{n-1}^{*}$ полином $Q_{n}(y)$ возрастает к бесконечности, и поэтому сушествует корень $a_{n}^{*}>a_{n-1}^{*}>0$. По индукции это означает, что утверждение леммы верно для всех $n=1,2, \ldots$

Лемма 6. Пусть

$$
f(x)=\mathbf{E} I\left\{M+x \geqslant a^{*}\right\} G(M+x)<\infty,
$$

где Функиия $G(x)$ такова, ито при всех $y \geqslant x \geqslant a^{*} \geqslant 0$

$$
G(y) \geqslant G(x) \geqslant G\left(a^{*}\right)=0 .
$$

Tогда для всех $x$

$$
f(x) \geqslant \mathbf{E} f(\xi+x)
$$

Д о к а з а т е л ь с т о. Неравенство (16) доказывает следуюшая цепочка соотношений, в которой используется свойство $M \stackrel{\text { law }}{=}(M+\xi)^{+}$(см. лемму 1$)$ :

$$
\begin{aligned}
f(x)= & \mathbf{E} I\left\{(M+\xi)^{+}+x \geqslant a^{*}\right\} G\left((M+\xi)^{+}+x\right)=\mathbf{E} I\left\{x \geqslant a^{*}, M+\xi<0\right\} G(x) \\
& +\mathbf{E} I\left\{M+\xi+x \geqslant a^{*}, M+\xi \geqslant 0\right\} G(M+\xi+x) \\
\geqslant & \mathbf{E} I\left\{M+\xi+x \geqslant a^{*}, M+\xi<0\right\} G(M+\xi+x) \\
& +\mathbf{E} I\left\{M+\xi+x \geqslant a^{*}, M+\xi \geqslant 0\right\} G(M+\xi+x)=\mathbf{E} f(x+\xi) .
\end{aligned}
$$

Лемма 7. Пусть $f(x)$ и $g(x)$ - неотричательнье функиии такие, что длғ $\operatorname{ecex} x$

$$
f(x) \geqslant g(x)
$$

$$
f(x) \geqslant \mathbf{E} f(\xi+x)
$$

Тогда для 6 cex $x$

$$
f(x) \geqslant \sup _{\tau \in \overline{\mathfrak{M}}_{0}^{\infty}} \mathbf{E} I\{\tau<\infty\} g\left(S_{\tau}+x\right) .
$$


Д о к а з а т е л в с т в о. Условия (17) и (18) означаљот, что функшия $f(x)$ есть эксцессивная мажоранта для функши $g(x)$, пля которой приведенное неравенство следует из теоремы Дуба о сохранении супермартингаљного свойства при случайной замене времени (см., например, [1], [3], [9]).

\section{§3. Доказательство теоремы 1}

Пусть $g(x)=\left(x^{+}\right)^{n}, \widehat{g}(x)=x^{n}$ и функция $\widehat{V}_{n}(x)$ определена в (5). Покажем, что выполнено (8), т.е.

$$
\widehat{V}_{n}(x)=\sup _{a \geqslant 0} E_{x} I\left\{\tau_{a}<\infty\right\} X_{\tau_{a}}^{n}=\mathbf{E} Q_{n}(M+x) I\left\{M+x \geqslant a_{n}^{*}\right\}
$$

Для этого заметим, что по лемме $3(\mathrm{~b})$

$$
E_{x} I\left\{\tau_{a}<\infty\right\} X_{\tau_{a}}^{n}=\mathbf{E} Q_{n}(M+x) I\{M+x \geqslant a\}
$$

где $Q_{n}(M+x) \geqslant 0$ на множестве $\{M+x \geqslant a\}$ для всех $a \in\left[a_{n}^{*}, \infty\right)$. Следовательно, $\mathrm{E} Q_{n}(M+x) I\{M+x \geqslant a\}$ является убываюшей функцией на $\left[a_{n}^{*}, \infty\right)$.

Пусть теперь $a \in\left[0, a_{n}^{*}\right]$. Из (13) находим, что

$$
\begin{aligned}
\mathbf{E} Q_{n}(M+x) I\{M+x \geqslant a\}= & x^{n}-\mathbf{E} Q_{n}(M+x) I\{M+x<0\} \\
& -\mathbf{E} Q_{n}(M+x) I\{0 \leqslant M+x<a\} .
\end{aligned}
$$

Пользуясь тем, что $Q_{n}(M+x) I\{0 \leqslant M+x \leqslant a\} \leqslant 0$ (см. лемму 5) и, значит, $\mathbf{E} Q_{n}(M+x) I\{0 \leqslant M+x<a\}$ является убываюшей функцией, заключаем, что $\mathbf{E} Q_{n}(M+x) I\{M+x \geqslant a\}$ является возрастаюшей функцией на $\left[0, a_{n}^{*}\right]$. Так как эта функция является также и убывающей на $\left[a_{n}^{*}, \infty\right)$ (это показано выше) и, очевидно, непрерывной (по свойству интеграла Лебега) при всех $a$, то она достигает максимума в точке $a=a_{n}^{*}$. Таким образом, (20) (оно же (8)) доказано.

Чтобы завершить доказательство, нам нужно только проверить неравенство (8), т.е. показать, что $\widehat{V}_{n}(x) \geqslant V_{n}(x)$ (как отмечалось в $§ 1$, противоположное неравенство очевипно). С этой целью рассмотрим функцио

$$
f(x)=\widehat{V}_{n}(x)=\mathbf{E} I\left\{M+x \geqslant a_{n}^{*}\right\} Q_{n}(M+x)
$$

и применим лемму 7 , беря $g(x)=\left(x^{+}\right)^{n}$. Проверим сначала условие $(17)$ при $x \in\left(0, a_{n}^{*}\right)$ (иначе оно очевишно). Для этого заметим, что при $x \in\left(0, a_{n}^{*}\right)$ ввиду леммы 5

$$
I\left\{M+x \geqslant a_{n}^{*}\right\} Q_{n}(M+x)=\left(Q_{n}(M+x)\right)^{+} .
$$

Тогда по неравенству Иенсена и лемме 4

$$
f(x)=\mathbf{E}\left(Q_{n}(M+x)\right)^{+} \geqslant\left(\mathbf{E} Q_{n}(M+x)\right)^{+}=\left(x^{+}\right)^{n}=g(x) .
$$

Условие (18) леммы 7 выполнено для функиия $G(y)=Q_{n}(y)$ в силу леммы 6.

Таким образом, функция $f(x)$ является эксцессивной мажорантой функии $g(x)=\left(x^{+}\right)^{n}$ и, значит, $f(x) \geqslant V_{n}(x)$. Но $f(x)=\widehat{V}_{n}(x)$, и, следовательно, $\widehat{V}_{n}(x) \geqslant V_{n}(x)$. Теорема 1 доказана.

\section{§4. Несколько замечаний}

3 а м е ч а н и е 4. Метод доказательства теоремы 1 может быть использован и для других функций $g(x)$. Для примера приведем следующий результат.

Теорема 2. Пусть $\mathbf{E} \xi<0 u g(x)=1-e^{-x^{+}}$. Положим

$$
a^{*}=-\ln \mathbf{E} e^{-M} \text {. }
$$

Тогда момент остановки

$$
\tau_{a^{*}}=\inf \left\{k \geqslant 0: X_{k} \geqslant a^{*}\right\}
$$

двлется оптимальным:

$$
V(x)=\sup _{\tau \in \overline{\mathfrak{M}}_{0}^{+\infty}} E_{x} g\left(X_{\tau}\right) I\{\tau<\infty\}=E_{x} g\left(X_{\tau_{a^{*}}}\right) I\left\{\tau_{a^{*}}<\infty\right\}
$$

при этом $V(x)=\mathbf{E}\left(1-e^{-M-x}\left(\mathbf{E} e^{-M}\right)^{-1}\right)^{+}$. 
Д о к а з а т е л ь с т в о. Мы наметим только схему доказательства, поскольку оно аналогично доказательству теоремы 1 (и даже проще).

Пусть $g(x)=1-e^{-x^{+}}$и

$$
\widehat{V}(x)=\sup _{a \geqslant 0} E_{x} I\left\{\tau_{a}<\infty\right\} g\left(X_{\tau_{a}}^{n}\right) .
$$

Покажем, что

$$
\widehat{V}(x)=\mathbf{E}\left(1-\frac{e^{-M-x}}{\mathbf{E} e^{-M}}\right)^{+}
$$

Для этого заметим, что по лемме 3(a) с $u=-1$ справедливо равенство

и, значит,

$$
E_{x} I\left\{\tau_{a}<\infty\right\} e^{-X_{\tau_{a}}}=\frac{\mathbf{E} I\{M+x \geqslant a\} e^{-(M+x)}}{\mathbf{E} e^{-M}}
$$

$$
q(a):=E_{x} I\left\{\tau_{a}<\infty\right\} g\left(X_{\tau_{a}}\right)=\mathbf{E} I\{M+x \geqslant a\}\left(1-\frac{e^{-(M+x)}}{\mathbf{E} e^{-M}}\right) .
$$

Заметим также, что функция $1-e^{-a} / \mathbf{E} e^{-M}$ является монотонной по $a$ с единственным корнем $a^{*}=-\ln \mathrm{E} e^{-M}$. Те же рассуждения, что и в доказательстве теоремы 1 , показывают, что $q(a)$ достигает максимума в точке $a=a^{*}$ и при этом

$$
\widehat{V}(x)=\mathbf{E} I\left\{M+x \geqslant a^{*}\right\}\left(1-\frac{e^{-(M+x)}}{\mathbf{E} e^{-M}}\right)=\mathbf{E}\left(1-\frac{e^{-M-x}}{\mathbf{E} e^{-M}}\right)^{+} .
$$

Чтобы завершить доказательство, нам нужно только проверить неравенство (8), т.е. показать, что $\widehat{V}(x) \geqslant V(x)$. С этой целью рассмотрим функцию

$$
f(x)=\widehat{V}(x)=\mathbf{E}\left(1-\frac{e^{-M-x}}{\mathbf{E} e^{-M}}\right)^{+}
$$

Условие (17) выполнено по неравенству Иенсена:

$$
f(x) \geqslant\left(1-\frac{\mathbf{E} e^{-M-x}}{\mathbf{E} e^{-M}}\right)^{+}=\left(1-e^{-x}\right)^{+}=g(x) .
$$

Условие (18) выполнено для функции $G(y)=\left(1-e^{-y} / \mathbf{E} e^{-M}\right)^{+}$в силу леммы 6. Все это приводит к доказательству теоремы 2.

3 а м е ч а н и е 5 . Решение задачи об оптимальной остановке на конечном интервале $\{0,1, \ldots, T\}$, состоящей в отыскании «цены»

$$
V(x, T)=\sup _{\tau \in \mathfrak{M}_{0}^{T}} E_{x} g\left(X_{\tau}\right), \quad x \in \mathbf{R}
$$

где супремум берется по всем марковским моментам $\tau, \tau \leqslant T<\infty$, можно получить в численном виде, используя, ках хорошо известно, метод «обратной индукции» (детали см., например, в [4], [11]). При больших $T$ реализашия этого метода может потребовать большого счета даже для простых распределений. Поэтому представляет интерес оценить скорость сходимости $V(x, T)$ при $T \rightarrow \infty$ к функции $V(x)$, найденной в теоремах 1 и 2 .

Теорема 3. Пусть $g(x)=\left(x^{+}\right)^{n}, n=1,2, \ldots$, uлu $g(x)=1-e^{-x^{+}}, u$ пусть $\mathbf{E} e^{\lambda \xi}<1$ для некоторого $\lambda>0$. Тогда суиествуют положсительнье константы $C(x)$ и с, не завислиие от $T$ и такие, ито дмя каждого $x \in \mathbf{R}$ при всех $T>0$

$$
0 \leqslant V(x)-V(x, T) \leqslant C(x) e^{-c T} .
$$

Д оказательст в о. Так как класс $\mathfrak{M}_{0}^{\infty}$ шире класса $\mathfrak{M}_{0}^{T}$, то $V(x) \geqslant$ $V(x, T)$. Чтобы получить верхнюю оценку (23), заметим, что $V(x, T) \geqslant$ $E_{x} g\left(X_{\min \left(\tau_{b}, T\right)}\right) \geqslant E_{x} g\left(X_{\tau_{b}}\right) I\left\{\tau_{b} \leqslant T\right\}$, где $\tau_{b}=\inf \left\{k \geqslant 0: X_{k} \geqslant b\right\}-$ оптимальный момент остановки для цены $V(x)$ и, согласно теоремам 1 или 2, параметр $b$ 
равен $a_{n}^{*}$ или $a^{*}-$ соответственно виду рассматриваемой функции $g(x)$. Так как $V(x)=E_{x} g\left(X_{\tau_{b}}\right) I\left\{\tau_{b}<\infty\right\}$, то получаем

$$
V(x)-V(x, T) \leqslant E_{x} g\left(X_{\tau_{b}}\right) I\left\{T<\tau_{b}<\infty\right\} .
$$

Ниже мы покажем, что

$$
P_{x}\left\{T<\tau_{b}<\infty\right\} \leqslant C(x) e^{-c T},
$$

где $C(x)$ и $c$ - некоторые положительные константы, не зависяшие от $T$. Если функция $g(x)$ ограничена (как в теореме 2), то отсюда и из (24) сразу следует (23). Этой же оценки (25) достаточно для справедливости утверждения (23) и в случае $g(x)=\left(x^{+}\right)^{n}$, $n=1,2, \ldots$, в силу неравенства $X_{\tau_{b}} \leqslant M$ в комбинации с леммой 2(b) и неравенством Гёльдера.

Пусть $\psi(u)$ определяется из соотношения

$$
\mathbf{E} e^{u \xi}=e^{\psi(u)} \quad(u<\theta=\sup \{u \geqslant 0: \psi(u)<\infty\}) .
$$

Заметим, что $\psi(u)$ - выпуклая функция и в силу условий теоремы $\theta>0$. Из этих свойств следует, что производная $\psi^{\prime}(0)=\mathbf{E} \boldsymbol{\xi}<0$ и существует положительное $\lambda_{0} \in(0, \theta)$ такое, что $\psi^{\prime}\left(\lambda_{0}\right)=0$ и $\psi\left(\lambda_{0}\right)<0$ (см., например, [2]). Чтобы теперь доказать (25), воспользуемся тем фактом, что процесс

$$
\exp \left\{\lambda\left(X_{k}-x\right)-k \psi(\lambda)\right\}, \quad k \geqslant 0 \quad(\lambda \in(0, \theta))
$$

является неотрицательным мартингалом с математическим ожиданием $\mathbf{E} \exp \left\{\lambda\left(X_{k}-\right.\right.$ $x)-k \psi(\lambda)\}=1$ и поэтому может быть использован для задания новой меры $\widehat{P}_{x}(A)$, $A \in \sigma\left(\bigcup_{k \geqslant 0} \mathscr{F}_{k}\right)$ такой, что для каждого $k \geqslant 0$ и множества $A \in \mathscr{F}_{k}$

$$
\widehat{P}_{x}(A)=E_{x} I\{A\} \exp \left\{\lambda_{0}\left(X_{k}-x\right)-k \psi\left(\lambda_{0}\right)\right\}
$$

(Это есть не что иное, как общеизвестное преобразование Эшера.) Из данных определений следует, что при $\lambda_{0} \in(0, \theta)$

$$
\begin{gathered}
E_{x} I\left\{T<\tau_{b}<\infty\right\} \exp \left\{\lambda_{0}\left(X_{\tau_{b}}-x\right)-\tau_{b} \psi\left(\lambda_{0}\right)\right\} \\
=\sum_{k=T+1}^{\infty} E_{x} I\left\{\tau_{b}=k\right\} \exp \left\{\lambda_{0}\left(X_{k}-x\right)-k \psi\left(\lambda_{0}\right)\right\} \\
=\sum_{k=T+1}^{\infty} \widehat{P}_{x}\left\{\tau_{b}=k\right\}=\widehat{P}_{x}\left\{T<\tau_{b}<\infty\right\} .
\end{gathered}
$$

Так как $X_{T_{b}} \geqslant b$, то

$$
P_{x}\left\{T<\tau_{b}<\infty\right\} \leqslant e^{\lambda_{0}(x-b)} e^{\psi\left(\lambda_{0}\right) T} \widehat{P}_{x}\left\{T<\tau_{b}<\infty\right\} .
$$

Ввиду того, что $\widehat{P}_{x}\left\{T<\tau_{b}<\infty\right\} \leqslant 1$, отсюда следует оценка (25) с константами $c=-\psi\left(\lambda_{0}\right)>0, C(x)=e^{\lambda_{0}(x-b)}, b=a_{n}^{*}$ или $b=a^{*}$ соответственно виду рассматриваемой функции $g(x)$.

Теорема 3 доказана.

3 а м е ч а н и е 6. Результаты работы непосредственным образом переносятся на случай непрерывного времени, когда вместо случайного блуждания $S_{n}$ рассматривается однородный процесс Леви. Этот перенос можно сделать либо с помошью предельного перехода от дискретного времени по аналогии с тем, как это сделано в [10] применительно к задаче об Американском опционе, либо с помошњю техники псевдодифференциальных операторов в контексте процессов Леви, описанной в монографии [3].

Авторы признательны Е. Шинджикашвили за обсуждение результатов работы. Первый автор также признателен Y. Miyahara и A. Shimizu за поддержку и дискуссии во время визита в Nagoya City University. 


\section{СПИСОК ЛИТЕРАТУРЫ}

1. Blackwell D. On optimal systems. - Ann. Math. Statist., 1954, v. 25, p. 394-397.

2. Боровков $A$. A. Вероятностные процессы в теории массового обслуживания. М.: Наука, $1972,368 \mathrm{c}$.

3. Boyarchenko S., Levendorskiž S.Z. Non-Gaussian Merton-Black-Scholes Theory. River Edge: World Scientific, 2002, 398 p. (Adv. Ser. Statist. Sci. Appl. Probab., v. 9.)

4. Роббинс Г., Сигмунд Д., Чао И. Теория оптималњных правил остановки. М.: Наука, 1977, $167 \mathrm{c}$.

5. Chow Y.S., Teicher T. Probability Theory: Independence, Interchangeability, Martingales. New York: Springer-Verlag, 1997, 488 p.

6. Darling D. A., Liggett T., Taylor H.M. Optimal stopping for partial sums. - Ann Math. Statist., 1972 , v. 43 , p. 1363-1368.

7. Dubins L. E., Savage L. J. Inequalities for Stochastic Processes (How to Gamble if You Must). New York: Dover, 1976, 255 p.

8. Kingman J. F. C. Inequalities in the theory of queues. - J. Roy. Statist. Soc. Ser. B 1970 , v. 32 , p. $102-110$.

9. Liu $Z$., Nain $P$., Towsley $D$. Bounds for a class of stochastic recursive equations. Math. Methods Oper. Res., 1999, v. 49, № 2, p. 325-333.

10. Mordecki E. Optimal stopping and perpetual options for Lévy processes. - Finance Stoch., 2002, v. 6, № 4, p. 473-493.

11. Ширяев А.Н. Статистический последовательный анализ. Оптиматьные правила остановки. М.: Наука, 1976, 272 с.

12. Stadje $W$. An iterative approximation procedure for the distribution of the maximum of a random walk. - Statist. Probab. Lett., 2000, v. 50, № 4, p. 375-381.

13. Schoutens $W$. Stochastic Processes and Orthogonal Polynomials. New York: SpringerVerlag, 2000, 163 p. (Lecture Notes in Statist., v. 146.)

14. Висков $O . B$. Случайное блуждание с непрерывной вверх компонентой и формула обрашения Лагранжа. - Теория вероятн. и ее примен., 2000, т. 45, в. 1, с. 166-175.

Поступила в редакцию

1.VII.2002

\section{(C) 2004 r. CAXAHEHКО А. и. О ПЕРЕХОДНЫХ ЯВЛЕНИЯХ В СЛУЧАЙНЫХ БЛУЖДАНИЯХ}

Пусть $\bar{S}_{n}=\max _{1 \leqslant k \leqslant n} \sum_{i=1}^{k} X_{i, n}$, где при каждом $n=1,2, \ldots$ последовательность $X_{1, n}, \ldots, X_{n, n}$ состоит из независимых и одинаково распределенных случайных величин с конечными положительными дисперсиями. В работе изучается задача о получении простых и неулучшаемых достаточных условий, типа условия Линдеберга, которые гарантировали бы сходимость нормированной величины $\left(\bar{S}_{n}-A_{n}\right) / B_{n}$ к некоторой невырожденной случайной величине при соответствуюшим образом подобранных постоянных $A_{n}$ и $B_{n}>0$. Упрощены, уточнены и усилены результаты, полученные ранее в этом направлении Ю.В. Прохоровым и А. А. Боровковым. В частности, подробно рассмотрен неисследованный ранее случай, когда $\mathrm{D} X_{1, n} \rightarrow 0$ при $n \rightarrow \infty$.

Ключевые слова и фразы: схема серий, максимум последовательных сумм, равномерная сходимость распределений, предельные распределения, принцип инвариантности, расстояние Прохорова.

* Юторский посударственный университет, ул. Чехова, 16, 628012 ХантыМансийск, Россия; e-mail: aisakh@hotmail.com 